\title{
MỘT SỐ YẾU TỐ ẢNH HƯởNG ĐẾN KỸ NĂNG GHI NHỚ TỪ TIẾNG ANH CỦA HỌC SINH LỚP 6
}

\author{
Đào Thị Diệu Linh* \\ Bộ môn Tâm lý - Giáo dục, Truờng Đại học Ngoại ngũ, ĐHQGHN, \\ Phạm Văn Đồng, Cầu Giấy, Hà Nội, Việt Nam \\ Nhận bài ngày 02 tháng 03 năm 2017 \\ Chỉnh sửa ngày 10 tháng 07 năm 2017; Chấp nhận đăng ngày 28 tháng 09 năm 2017
}

Tóm tắt: Kỹ năng ghi nhớ từ là một trong những kỹ năng quan trọng cần thiết cho hoạt động học tập ngoại ngữ nói chung và học tiếng Anh nói riêng. Nghiên cứu 216 học sinh lớp 6 và 11 giảng viên tiếng Anh ở 2 trường trung học cơ sở ở Hà Nội bằng các phương pháp như quan sát, thực nghiệm, điều tra, phỏng vấn về kỹ năng này, chúng tôi thấy rằng kỹ năng ghi nhớ từ tiếng Anh của sinh lớp 6 chịu sự ảnh hưởng của một số yếu tố như: nhận thức của học sinh về vai trò của từ vựng, hứng thú học tập tiếng Anh, phương pháp giảng dạy của giáo viên, các phương tiện, trang thiết bị phục vụ cho hoạt động học tập tiếng Anh... Trong những yếu tố này, về phía học sinh (yếu tố chủ quan), hứng thú học tập của các em có ảnh hưởng rõ rệt nhất. Mức độ hứng thú học tiếng Anh của học sinh có mối tương quan thuận và chặt chẽ với mức độ ghi nhớ cách dùng từ tiếng Anh và mức độ ghi nhớ các đặc điểm của tù tiếng Anh. Về phía khách quan, yếu tố phương tiện, trang thiết bị phục vụ hoạt động học tập tiếng Anh của học sinh là yếu tố có ảnh hưởng lớn nhất tới mức độ học sinh ghi nhớ từ. Có thể nói, mức độ học sinh thường xuyên sử dụng tiếng Anh để trò chuyện, giao tiếp càng nhiều bao nhiêu, mức độ ghi nhớ, tái hiện và vận dụng từ tiếng Anh càng hiệu quả bấy nhiêu. Giáo viên cần nhận thức được những đặc điểm học tập này của học sinh lớp 6 để tổ chức giờ học cho hiệu quả, kích thích được hứng thú học tập, tính tích cực học tập cho các em.

Tù khoá: kỹ năng ghi nhớ, mức độ ghi nhớ từ tiếng Anh, yếu tố ảnh hưởng, hứng thú học tập

\section{1. Đặt vấn đề}

Trong một thế giới hội nhập như ngày nay, ngoại ngữ là một công cụ hữu hiệu và không thể thiếu để mỗi quốc gia hội nhập và phát triển. Chính vì vậy, việc dạy và học ngoại ngữ đã và đang được Đảng và Nhà nước ta hết sức quan tâm. Rất nhiều dự án, đề án, chính sách liên quan đến giáo dục ngoại ngữ đã được triển khai. Điển hình như Đề án dạy và học ngoại ngữ trong hệ thống giáo dục quốc dân giai đoạn 2008 - 2020, thường gọi tắt là Đề án 2020. Trong Đề án, Bộ Giáo dục và Đào tạo đã khẳng định một trong những kết quả cần đạt được là: Chương trình tiếng Anh cấp trung học cơ sở (THCS) (lớp $6,7,8,9$ ) được áp dụng từ lớp 6 với thời

\footnotetext{
* ĐT.: 84-912170182

Email: daodieulinh1980@gmail.com
}

lượng 3 tiết/tuần. Tổng số tiết của toàn cấp THCS là 420 tiết. Kết thúc cấp THCS, học sinh (HS) sẽ đạt trình độ bậc 2 theo khung năng lực ngoại ngữ ở cả 4 kỹ năng nghe, nói, đọc, viết (Bộ Giáo dục và Đào tạo, 2008).

Đối với hoạt động giảng dạy ngoại ngữ, mục đích cuối cùng chính là để hình thành năng lực ngoại ngữ cho người học. Để có thể sử dụng ngoại ngữ một cách hiệu quả đòi hỏi người học không chỉ ghi nhớ được cách phát âm, từ vựng hay ngữ pháp (ba thành tố cơ bản của một ngôn ngữ) mà còn phải biết cách sử dụng những từ đã được học, vận dụng chúng một cách linh hoạt trong những tình huống giao tiếp khác nhau. Người học thực hiện các hoạt động lời nói (HĐLN) ngoại ngữ một cách thành thạo khi họ biết cách vận dụng linh hoạt vốn từ vựng đã học, sử dụng chúng để thể hiện ý cuả mình trong giao tiếp. 
Đối với HS lớp 6, đây là năm học đầu tiên ở bậc THCS các em được học ngoại ngữ với tư cách là một môn học bắt buộc. HS lớp 6 còn gặp nhiều khó khăn khi tiếp xúc với môn học này. Để giúp học sinh lớp 6 khắc phục được những khó khăn trong học tập cũng như để nâng cao khả năng ghi nhớ từ tiếng Anh cho HS, chúng tôi đã thực hiện những nghiên cứu cụ thể về vấn đề này. Những kết quả nghiên cứu một số yếu tố ảnh hưởng đến kỹ năng ghi nhớ (KNGN) từ tiếng Anh của HS lớp 6 nói riêng, hoạt động học tập tiếng Anh nói chung sẽ giúp chúng tôi tìm ra những biện pháp cụ thể góp phần giúp cho quá trình dạy và học ngoại ngữ đạt hiệu quả cao hơn. Đây cũng là những căn cứ khoa học hữu ích cho các giáo viên $(\mathrm{GV})$ giảng dạy tiếng Anh ở tất cả các cơ sở có đào tạo, giảng dạy tiếng Anh ở nước ta.

\section{Khách thể và phương pháp nghiên cứu}

Nghiên cứu được thực hiện trên 216 HS lớp 6 và $11 \mathrm{GV}$ giảng dạy tiếng Anh ở 02 trường THCS trên địa bàn Hà Nội (trường THCS Cát Linh, quận Đống Đa và trường THCS Phương Canh, quận Nam Từ Liêm).

Đối với nghiên cứu chung về KNGN từ tiếng Anh của HS lớp 6, chúng tôi sử dụng kết hợp các phương pháp như: phương pháp quan sát, phương pháp thực nghiệm nhận biết, phương pháp điều tra bằng bảng hỏi, phương pháp phỏng vấn, phương pháp chuyên gia... Riêng những kết quả nghiên cứu về một số yếu tố ảnh hưởng đến KNGN từ tiếng Anh của HS lớp 6 được sử dụng chủ yếu từ phương pháp điều tra bằng bảng hỏi và phương pháp phỏng vấn. Những kết quả thu được từ các phương pháp trên được xử lý bằng phần mềm SPSS 20.0 (SPSS - Statistical Package for the Social Sciences - là một phần mềm thống kê thường được sử dụng trong nghiên cứu xã hội, đặc biệt là trong tâm lý học, tiếp thị và xã hội học).

Trong bảng hỏi dành cho GV (14 câu hỏi) và $H S$ (14 câu hỏi), ngoài những câu hỏi mở và những câu hỏi xếp thứ bậc, các câu hỏi còn lại đều được thiết kế có các phương án trả lời theo 5 mức độ (thang đo Likert) và được cho điểm từ thấp tới cao tương ứng từ 1 đến 5 điểm. Cụ thể:

+ Rất không đồng ý/Không bao giờ: 1 điểm

+ Không đồng ý/ Hiếm khi: 2 điểm

+ Lưỡng lự/ Thỉnh thoảng: 3 điểm

+ Đồng ý/ Thường xuyên: 4 điểm

+ Rất đồng ý/ Rất thường xuyên: 5 điểm

Các thông số và phép thống kê được dùng trong nghiên cứu là phân tích thống kê mô tả và phân tích thông kê suy luận, cụ thể:

* Phân tích thống kê mô tả. Các chỉ số được dùng trong phân tích thống kê mô tả gồm:

- Điểm trung bình (ĐTB) (Mean) được dùng để tính điểm đạt được của những câu hỏi được thiết kế có nhiều mức độ khác nhau.

- Độ lệch chuẩn (SD - Standard deviation) được dùng để mô tả mức độ phân tán hay tập trung của các câu trả lời được lựa chọn.

- Tần suất, chỉ số phần trăm phương án trả lời của các câu hỏi đóng trong phiếu điều tra.

* Phân tích thông kê suy luận. Các phép thống kê suy luận được sử dụng gồm:

- Phân tích so sánh: chủ yếu sử dụng phép so sánh giá trị trung bình. Các giá trị trung bình được coi là khác nhau có ý nghĩa về mặt thống kê khi xác suất $\mathrm{p}<0,05$. Để so sánh hai nhóm, chúng tôi sử dụng phép kiểm định $\mathrm{T}$ về độc lập giữa hai mẫu (T- Test).

- Phân tích tương quan nhị biến: chúng tôi sử dụng phép phân tích tương quan để xác định tương quan giữa các yếu tố ảnh hưởng với nhóm kỹ năng 1 (kỹ năng ghi nhận đặc điểm từ tiếng Anh) và nhóm kỹ năng 2 (kỹ năng ghi nhận cách dùng từ tiếng Anh). Mục đích là tìm hiểu mức độ (hay độ mạnh) liên kết giữa hai biến này. Mức độ này được đo bởi hệ số tương quan Pearson hoặc Spearman (r) có giá trị từ $(-1)$ đến $(+1)$. Giá trị này cho biết độ mạnh và hướng của mối liên hệ: nếu giá trị $(+), r>0$ có nghĩa là giữa chúng có mối liên hệ thuận; nếu giá trị (-), $\mathrm{r}<0$ là thể hiện mối tương quan nghịch; nếu $r=0$ thì hai biến số 
đó không có mối quan hệ với nhau. Mức độ ý nghĩa của mối quan hệ dựa vào quan hệ xác suất (p). Nếu $\mathrm{p}<0,05$ thì giá trị $\mathrm{r}$ có ý nghĩa cho việc phân tích mối quan hệ giữa hai biến.

Trong khuôn khổ của nghiên cứu này, chúng tôi chỉ tập trung tìm hiểu hai nhóm yếu tố ảnh hưởng là yếu tố chủ quan và yếu tố khách quan. Cụ thể là các yếu tố: nhận thức của học sinh về vai trò của từ vựng đối với HĐLN tiếng Anh, hứng thú học tiếng Anh của học sinh (thuộc nhóm yếu tố chủ quan); phương pháp dạy học của $\mathrm{GV}$, phương tiện, trang thiết bị phục vụ học tập tiếng Anh (thuộc nhóm yếu tố khách quan).

Riêng về cơ sở lí luận xây dựng các nhóm kỹ năng thành phần của KNGN từ tiếng Anh, chúng tôi dựa trên những quan điểm cơ bản sau đây:

Một là, theo Karlin (1987), khi phân loại các kĩ năng đọc (Reading skills) thành năm nhóm nhỏ, ông đã đề cập đến 3 kỹ năng thành phần là kĩ năng nhận diện từ (word recognition skills), kĩ năng hiểu nghĩa của từ (word meaning skills) và kĩ năng đọc hiểu văn bản (comprehensive skills). Trong đó, Karlin khẳng định các kỹ năng này bao gồm các biểu hiện như: việc sử dụng bối cảnh, phân tích âm thanh, phân tích cấu trúc và sử dụng từ (trong kỹ năng nhận diện từ); việc sử dụng bối cảnh, phân tích cấu trúc, nhận diện từ đa nghĩa và những từ chỉ số lượng (trong kỹ năng hiểu nghĩa của từ); việc nhận diện nghĩa đen của từ, nghĩa phỏng đoán (nghĩa bóng), sự đánh giá và xác nhận tài liệu (trong kỹ năng đọc hiểu văn bản).

Hai là, dựa vào mô hình các cấp độ xử lý thông tin (the levels of processing model, Craik and Lockhart, 1972) cho thấy cách chúng ta mã hóa thông tin sẽ phản ánh việc chúng ta ghi nhớ tốt đến đâu. Thông tin được lưu giữ ở cấp độ nào phụ thuộc rất lớn vào việc thông tin đó được mã hóa ra sao. Cấp độ xử lý thông tin càng sâu bao nhiêu (mức độ sâu - ghi nhớ ngữ nghĩa - semantic), thông tin càng dễ dàng tái hiện được tốt bấy nhiêu (Craik and Brown, 2000). Điều đó cho thấy những thông tin ban đầu khi dạy ngoại ngữ rất quan trọng, những thông tin về cách đọc, cách viết, ngữ nghĩa và cách sử dụng từ sẽ được mã hóa trên não bộ và là cơ sở để tiếp nhận và liên kết với các thông tin tiếp theo.

Trên cơ sở những quan điểm trên, KNGN từ tiếng Anh được nghiên cứu cụ thể và được chia thành ba nhóm kỹ năng thành phần là: kỹ năng ghi nhận đặc điểm từ tiếng Anh, kỹ năng ghi nhận cách dùng từ tiếng Anh, kỹ năng sử dụng cách thức ghi nhớ từ tiếng Anh. Trong phạm vi của bài báo, chúng tôi sẽ đề cập tới một số yếu tố ảnh hưởng và mối tương quan của nó tới hai nhóm kỹ năng ghi nhận đặc điểm của từ và ghi nhận cách dùng từ tiếng Anh của HS lớp 6.

\section{Kết quả nghiên cứu và diễn giải}

\subsection{Thực trạng nhũng yếu tố chủ quan ảnh} huơong đến kỹ năng ghi nhớ tù tiếng Anh của hoc sinh lóp 6

Để tìm hiểu những yếu tố chủ quan ảnh hưởng tới $\mathrm{KNGN}$ từ tiếng Anh của HS lớp 6, trong phạm vi của nghiên cứu này, chúng tôi thiết kế các bảng hỏi nhằm tìm hiểu về hứng thú học tiếng Anh và nhận thức của $\mathrm{HS}$ về vai trò của từ vựng trong HĐLN tiếng Anh.

\subsubsection{Nhận thức của học sinh lớp 6 về vai trò của tù trong hoạt động lời nói tiếng Anh}

Từ vựng là một trong những thành tố quan trọng cấu thành nên một ngôn ngữ cụ thể. Đã có nhiều nghiên cứu cũng như các bài viết học thuật về vai trò của từ vựng cũng như việc học từ vựng tới hoạt động học tập ngoại ngữ. Việc học từ vựng cũng như vốn từ vựng phong phú sẽ giúp cho các kỹ năng nghe, nói, đọc, viết được thực hiện dễ dàng hơn (Nation, Paul 1994), hay người học với vốn từ vựng phong phú hơn có thể sử dụng những vốn từ đó để học tập nhiều hơn (Folse, Keith S. 2004). Vì thế chúng tôi cho rằng nhận thức của $\mathrm{HS}$ về vai trò của từ vựng và việc học từ vựng có ảnh 
hưởng nhất định tới hoạt động học tập của các em. Để hiểu rõ hơn về vấn đề này, chúng tôi đã thu thập ý kiến của HS, kết quả nghiên cứu cho thấy đa số HS nhận thức được vai trò quan trọng của từ vựng. Chỉ có một tỉ lệ rất ít HS đánh giá vai trò của từ vựng là không quan trọng. Cụ thể kết quả nghiên cứu được thể hiện trong bảng sau:

Bảng 1. Nhận thức của HS về vai trò của từ vựng trong HĐLN tiếng Anh

vựng nhưng những con số trên là những tín hiệu khả quan cho thấy vai trò của từ vựng đã được khá nhiều HS nhận thức đúng đắn.

Tìm hiểu mối tương quan giữa nhận thức của $\mathrm{HS}$ về vai trò của từ và việc học từ với các mức độ ghi nhớ từ của $\mathrm{HS}$, chúng tôi thấy rằng chúng có tương quan thuận với nhau nhưng không mạnh. Cụ thể, tương quan giữa nhận thức về vai trò của từ tiếng Anh với nhóm kỹ năng ghi nhận đặc điểm từ tiếng Anh có $\mathrm{r}=0.29$; với nhóm kỹ năng ghi nhận cách dùng từ tiếng Anh

\begin{tabular}{|c|c|c|c|c|c|c|c|}
\hline \multirow{2}{*}{ TT } & \multirow{2}{*}{$\begin{array}{c}\text { Các mệnh đề } \\
\text { (MĐ) }\end{array}$} & $\begin{array}{c}\text { Rất không } \\
\text { đồng ý }\end{array}$ & $\begin{array}{c}\text { Không } \\
\text { đồng ý }\end{array}$ & Lưỡng lự & Đồng ý & $\begin{array}{c}\text { Rất } \\
\text { đồng ý }\end{array}$ & \multirow{2}{*}{ (ĐTB) } \\
\hline 1 & MĐ 1* & 57.1 & 27.3 & 9.9 & 3.5 & 2.1 & 4.3 \\
\hline 2 & MĐ 2 & 6.8 & 3.6 & 7.1 & 47.0 & 35.6 & 3.97 \\
\hline 3 & MĐ 3 & 4.2 & 9.2 & 17.3 & 41.7 & 27.6 & 3.78 \\
\hline 4 & MĐ 4 & 3.5 & 10.6 & 22.2 & 35.2 & 28.5 & 3.75 \\
\hline 5 & MĐ 5 & 3.2 & 0.7 & 4.3 & 39.4 & 52.5 & 4.34 \\
\hline \multicolumn{7}{|c|}{ ĐTB chung } \\
\hline
\end{tabular}

Chú thích: Mệnh đề có dấu * được cho điểm ngược lại

MĐ 1: Từ vựng không có vai trò gì đối với việc học tiếng Anh

MĐ 2: Từ vựng là một trong 3 yếu tố cơ bản của tiếng Anh nói riêng và ngôn ngữ nói chung

MĐ 3: Phải học từ vựng thì mới học tốt tiếng Anh

MĐ 4: Học ngoại ngữ nào cũng cần phải học từ vựng

MĐ 5: Phải ghi nhớ thật nhiều từ tiếng Anh thì mới có thể giao tiếp bằng tiếng Anh tốt.

Rất nhiều HS "đồng ý" và "rất đồng ý" với những mệnh đề thể hiện vai trò tích cực của từ vựng và việc học từ vựng trong $\mathrm{HĐLN}$ tiếng Anh. ĐTB chung của các câu trả lời khá cao đạt 4.03/5 điểm. Hơn một nửa số HS được hỏi đều cho rằng "phải ghi nhớ thật nhiều từ tiếng Anh thì mới có thể giao tiếp bằng tiếng Anh tốt" (chiếm 52.5\%), đa số các em cũng thể hiện sự không đồng tình với quan điểm phủ nhận vai trò của từ vựng đối với việc học tiếng Anh (chiếm 57.1\%). Mặc dù vẫn còn một số HS đánh giá không đúng hoặc lưỡng lự chưa nhận thức rõ ràng được vai trò của từ có $\mathrm{r}=0.24(\mathrm{p}<0.01)$. Điều đó cho thấy nhận thức của $\mathrm{HS}$ về vai trò của từ vựng có ảnh hưởng tới việc $\mathrm{HS}$ ghi nhớ từ và cách dùng từ nhưng sự ảnh hưởng này không mạnh. Nhiều HS có nhận thức đúng đắn về vai trò của từ vựng đối với việc học ngoại ngữ nói chung và học tiếng Anh nói riêng, tuy nhiên, con số này mới chỉ dừng ở mức độ nhận thức của các em chứ điều đó chưa cho thấy HS học từ vựng hiệu quả hơn và có KNGN từ tốt hơn. Nói cách khác, có thể HS có nhận thức đúng đắn về vai trò của từ vựng, biết rằng việc học từ vựng là quan trọng và cần thiết, tuy nhiên, điều đó không có nghĩa là HS sẽ tự giác học, nhận thức đúng chưa đủ để trở thành động lực thúc đẩy HS ghi nhớ từ tốt hơn.

\subsubsection{Hưng thú học tiếng Anh của họ sinh} lóp 6

Yếu tố chủ quan thứ hai mà chúng tôi tập trung nghiên cứu là hứng thú học tập tiếng Anh của HS lớp 6 . Hứng thú là thái độ đặc biệt của cá nhân đối với đối tượng nào đó, vừa có ý nghĩa đối với cuộc sống, vừa có khả năng mang lại khoái cảm cho cá nhân trong quá trình hoạt động (Nguyễn Quang Uẩn, 2011). Vì thế, khi cá nhân 
có hứng thú với một đối tượng nào đó, thì đối tượng đó bao giờ cũng được cá nhân ý thức, hiểu ý nghĩa của nó đối với cuộc sống của họ. Hơn nữa ở cá nhân đó xuất hiện một tình cảm đặc biệt đối với nó, do đó hứng thú lôi cuốn hấp dẫn chủ thể về phía đối tượng của nó tạo ra tâm lý khát khao tiếp cận, "thâm nhập" vào đối tượng. Vì thế, hứng thú bao hàm trong nó cả yếu tố nhận thức, sự say mê, hấp dẫn, cuốn hút về phía đối tượng, đồng thời thể hiện cảm xúc của chủ thể khi tiếp cận với đối tượng đó cũng như những hành động tiếp cận tới đối tượng. Do đó, về hứng thú của HS khi học tiếng Anh, chúng tôi tập trung khai thác ở một số khía cạnh như: nhận thức của HS về vai trò của môn tiếng Anh, cảm xúc của HS khi học tiếng Anh và những hành động trong và ngoài giờ lên lớp của HS.

Kết quả thu được từ câu hỏi về nhận thức của HS cho thấy đa số HS lớp 6 nhận thức được việc học tiếng Anh là cần thiết để nâng cao kiến thức (chiếm $87.7 \%$ ) và cần thiết cho cuộc sống (chiếm 81.2\%). Tuy nhiên, mặc dù biết môn học này có vai trò quan trọng trong cuộc sống sau này nhưng nhiều HS cũng khẳng định mình học môn tiếng Anh vì đây là môn thi tốt nghiệp (42.4\%).

Về mặt cảm xúc, chúng tôi tìm hiểu xem HS có thực sự thích thú và thỏa mãn khi được học môn tiếng Anh hay không. Kết quả điều tra được trình bày ở bảng sau đây:

Bảng 2. Biểu hiện về mặt cảm xúc của HS lớp 6 khi học môn tiếng Anh
ĐTB càng cao thì mức độ cảm xúc dương tính, sự hài lòng, thỏa mãn khi được học môn tiếng Anh càng lớn. Có thể nhận thấy mức độ thích thú của HS khi học môn học này ở mức khá. Số lượng $\mathrm{HS}$ cảm thấy thích thú và rất thích thú khi được học môn tiếng Anh chiếm trên $50 \%$, tuy nhiên cũng có khá nhiều HS thỉnh thoảng mới cảm thấy thích thú khi học môn học này. Số liệu cũng cho thấy mặc dù số lượng HS cảm thấy nặng nề (học tiếng Anh như một gánh nặng) chiếm tỉ lệ rất thấp nhưng nhiều em cũng không hoàn toàn hay thực sự thích thú và thỏa mãn với môn học. Có thể nói, bên cạnh đa số HS thích và rất thích học tiếng Anh thì vẫn còn khá nhiều em thờ ơ, khó nói rõ tâm trạng, thái độ của mình với môn học.

Về các biểu hiện của HS trong và ngoài giờ học, số liệu thu được từ bảng hỏi của chúng tôi cũng cho thấy đa số HS luôn chú ý và ghi chép bài đầy đủ ở trên lớp (chiếm 90.1\%) tuy nhiên các em vẫn chưa chủ động và thực sự say mê với môn học này. Có 49.6\% HS chỉ làm các bài tập GV giao cho, thỉnh thoảng mới làm thêm các bài khác, nhiều HS chỉ học tiếng Anh ở trên lớp, khi GV giao bài thì mới làm thêm ở nhà $(35.9 \%)$. Điều này khá phù hợp với thời gian tự học của HS lớp 6 khi 32\% HS khẳng định thời gian tự học tiếng Anh ở nhà ít hơn 1 giờ. Những con số này cho thấy nhiều HS chưa thực sự hứng

\begin{tabular}{|c|c|c|c|c|c|c|c|}
\hline \multirow{2}{*}{ TT } & \multirow{2}{*}{ Các biểu hiện } & \multicolumn{7}{|c|}{ Tỷ lệ \% } & \multirow{2}{*}{ ĐTB } \\
\cline { 3 - 7 } & & $\begin{array}{c}\text { Không } \\
\text { bao giờ }\end{array}$ & $\begin{array}{c}\text { Hiếm } \\
\text { khi }\end{array}$ & $\begin{array}{c}\text { Thỉnh } \\
\text { thoảng }\end{array}$ & $\begin{array}{c}\text { Thường } \\
\text { xuyên }\end{array}$ & $\begin{array}{c}\text { Rất thuoòng } \\
\text { xuyên }\end{array}$ & \\
\hline 1 & Học tiếng Anh thật nặng nề* & 64.5 & 18.8 & 15.2 & 1.4 & & 4.43 \\
\hline 2 & Em không thích học tiếng Anh* & 60.5 & 26.0 & 10.3 & 3.2 & & 4.36 \\
\hline 3 & $\begin{array}{c}\text { Bình thường, khó nói rõ tâm } \\
\text { trạng của mình }\end{array}$ & 25.8 & 31.2 & 31.5 & 11.1 & 0.4 & 2.25 \\
\hline 4 & Em thấy thích thú & 4.9 & 7.4 & 26.1 & 56.9 & 4.6 & 3.48 \\
\hline 5 & Em thấy rất thích thú và thỏa mãn & 6.8 & 13.3 & 28.0 & 50.5 & 1.4 & 3.21 \\
\hline \multicolumn{7}{|c|}{ ĐTB chung } \\
\hline
\end{tabular}

Chú thích: nhũng mệnh đề có dấu * được cho điểm ngược lại thú và chưa thực sự đầu tư thời gian cho môn tiếng Anh, ngoài thời gian học ở trên lớp, 
nhiều em không ôn tập thêm nếu không có bài cô giáo giao cho.

Kết quả xử lý số liệu về mối tương quan giữa hứng thú học tiếng Anh với mức độ ghi nhớ từ của HS (tính theo ĐTB) cho thấy đây là mối tương quan thuận và khá mạnh, thể hiện ở sơ đồ sau: mức độ chú ý nghe giảng và ghi chép bài ở trên lớp mà chưa dành thời gian tự học và luyện tập ngoài giờ lên lớp. Điều đó cho thấy mức độ hứng thú chưa đạt mức cao, HS chưa thực sự hứng thú với hoạt động học tập này, bởi khi chúng ta thực sự hứng thú với hoạt động nào đó thì phải thể hiện

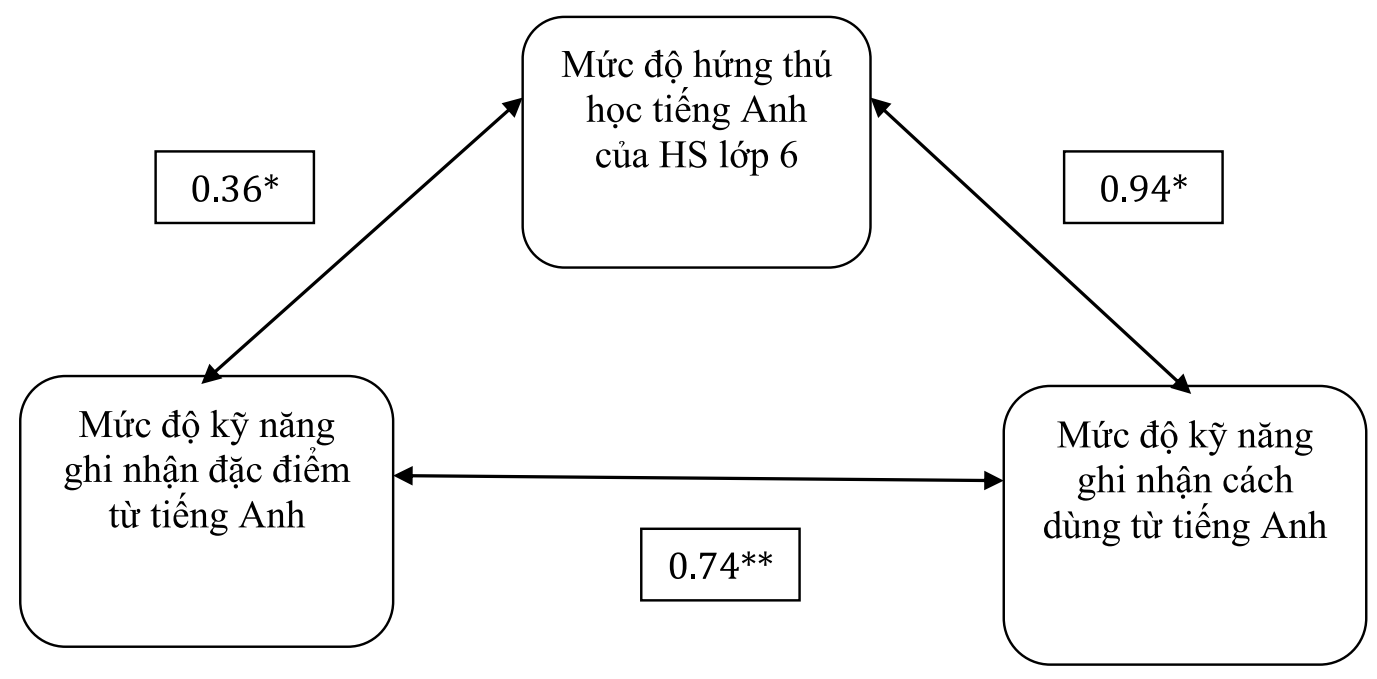

Chú thích: ${ }^{*} p<0.05 ; * * p<0.01$

Sơ đồ 1 . Tương quan giữa hứng thú học tiếng Anh và nhóm kỹ năng 1 (ghi nhận đặc điểm từ tiếng Anh) và nhóm kỹ năng 2 (ghi nhận cách dùng từ tiếng Anh)

Như vậy, hứng thú học tiếng Anh có ảnh hưởng không nhỏ tới hiệu quả của KNGN từ tiếng Anh. Trong đó, tương quan giữa hứng thú học tiếng Anh tới nhóm kỹ năng ghi nhận cách dùng từ tiếng Anh chặt chẽ hơn so với tương quan giữa hứng thú học tiếng Anh và kỹ năng ghi nhận đặc điểm từ tiếng Anh. Có thể nói mức độ hứng thú học tiếng Anh càng cao thì mức độ kỹ năng ghi nhận cách dùng từ và kỹ năng ghi nhận đặc điểm từ tiếng Anh càng cao và ngược lại.

Tóm lại, đa số HS lớp 6 thấy thích thú và rất thích thú khi học môn tiếng Anh nhưng vẫn còn một số em chưa chủ động dành thời gian, chưa chủ động, tích cực khi học tiếng Anh. Nhiều HS mới chỉ dừng ở ở sự thỏa mãn khi được hoạt động, thời gian mà chúng ta dành cho hoạt động ấy và thể hiện ở sự say mê với hoạt động ây. Do đó, ở đây, HS chỉ mới trả lời là thấy vui, thấy thích thú khi được học nhưng số lượng các em tự giác học tập, mày mò học thêm (ngoài các bài tập GV giao cho) thì còn rất hạn chế.

Mặt khác xét về mối tương quan, hứng thú học tiếng Anh tỉ lệ thuận với hiệu quả ghi nhớ các đặc điểm từ tiếng Anh và đặc biệt mức độ hứng thú học tiếng Anh có ảnh hưởng mạnh đến mức độ $\mathrm{HS}$ ghi nhớ được từ và cách dùng từ tiếng Anh đã học. HS càng hứng thú học tập bao nhiêu thì càng dễ dàng ghi nhớ được từ và các cách sử dụng từ đó bấy nhiêu. Vì vậy, nếu mức độ HS hứng thú với hoạt động học tập tiếng Anh càng cao. mức độ ghi nhớ từ của HS càng cao. 
3.2. Thực trạng nhũ̃ng yếu tố khách quan ảnh huởng tới kỹ năng ghi nhớ tù tiếng Anh của hoc sinh lớp 6

Tìm hiểu về những yếu tố khách quan ảnh hưởng tới KNGN từ tiếng Anh của $\mathrm{HS}$ lớp 6, nghiên cứu tập trung vào 2 yếu tố cơ bản là phương pháp giảng dạy của $\mathrm{GV}$ và những phương tiện, trang thiết bị phục vụ học tập. Những kết quả này thể hiện lần lượt ở những phần sau đây:

\subsubsection{Phuoong pháp dạy học của giáo viên}

Có rất nhiều phương pháp dạy học khác nhau như thuyết trình, vấn đáp, dạy học theo tình huống... Mỗi phương pháp có những ưu, nhược điểm riêng, có tác động không nhỏ tới hiệu quả học tập ở HS nói chung và hiệu quả của việc ghi nhớ từ tiếng Anh nói riêng. Trên thực tế có thể có những phương pháp giảng dạy khác nữa, nhưng trong kết quả mà chúng tôi thu nhận được, các phương pháp mà $\mathrm{GV}$ sử dụng chủ yếu là các phương pháp được trình bày dưới đây, trong phần câu hỏi mở để $\mathrm{GV}$ và $\mathrm{HS}$ điền các phương pháp khác (nếu có) thì kết quả thu được rất hạn chế. Kết quả khảo sát thực tiễn cho thấy ĐTB của các phương pháp và thứ bậc của chúng như sau:

Bảng 3. Những phương pháp giáo viên thường sử dụng khi giảng dạy tiếng Anh

\begin{tabular}{|c|l|c|c|}
\hline TT & $\begin{array}{c}\text { Phương pháp dạy } \\
\text { học }\end{array}$ & ĐTB & Xếp thứ bậc \\
\hline 1 & Thuyết trình & 4.83 & 1 \\
\hline 2 & Vấn đáp & 3.84 & 2 \\
\hline 3 & $\begin{array}{l}\text { Trực quan (sử dụng } \\
\text { tranh ảnh minh họa, } \\
\text { các đoạn video clip, } \\
\text { mô hình...) }\end{array}$ & 3.63 & 3 \\
\hline 4 & Thực hành & 3.04 & 6 \\
\hline 5 & $\begin{array}{l}\text { Đặt và giải quyết vấn } \\
\text { đề }\end{array}$ & 3.31 & 5 \\
\hline 6 & Hoạt động nhóm & 2.36 & 4 \\
\hline
\end{tabular}

Ở câu hỏi này, chúng tôi yêu cầu $G V$ và HS xếp thứ bậc các phương pháp dạy học, đánh số thứ tự từ một đến hết, phương pháp được sử dụng nhiều nhất tương ứng với số một (1), sau đó khi xử lý số liệu, các phương án này sẽ được cho điểm ngược lại, phương pháp được sử dụng nhiều nhất sẽ được tính điểm cao nhất. Vì thế, ở bảng số liệu trên, ĐTB càng cao nghĩa là mức độ sử dụng phương pháp đó càng nhiều. Từ bảng số liệu có thể thấy thuyết trình là phương pháp được sử dụng nhiều nhất, sau đó là phương pháp vấn đáp và phương pháp dạy học trực quan. Đây là 3 phương pháp được sử dụng phổ biến nhất. Chúng tôi cũng nhận thấy rằng $\mathrm{GV}$ thường sử dụng phối hợp các phương pháp, thuyết trình là phương phương pháp không thể thiếu để cung cấp và giải thích các đơn vị kiến thức cho HS. Cùng với phương pháp thuyết trình, GV sử dụng xen kẽ các câu hỏi (phương pháp vấn đáp) và sử dụng các tranh ảnh minh họa tương ứng với nội dung bài học (phương pháp dạy học trực quan). Phương pháp dạy học bằng cách tổ chức các hoạt động theo nhóm có ĐTB thấp nhất. Qua các buổi dự giờ, chúng tôi nhận thấy GV sử dụng phương pháp luyện tập và làm việc theo nhóm chỉ dừng ở mức cho HS luyện tập, thực hành các mẫu câu tiếng Anh theo cặp (work in pair). Phương pháp chia nhóm (work in groups) ít được sử dụng.

Trong các phương pháp $\mathrm{GV}$ thường sử dụng trên, chúng tôi đưa ra câu hỏi "Trong các phương pháp trên, em thích học theo phương pháp nào nhất? Vì sao?”. Kết quả cho thấy 29\% HS thích học thông qua phương pháp hoạt động nhóm (chiếm tỉ lệ cao nhất), tiếp đó là phương pháp trực quan $(24.9 \%)$, phương pháp thực hành $(17.1 \%)$ và thuyết trình (13.4\%). Như vậy, HS thích nhất là được học tiếng Anh bằng cách tham gia hoạt động nhóm và học qua các tranh ảnh minh họa, các đoạn phim, các bài hát mà $\mathrm{GV}$ sử dụng. Lý do các em đưa ra rất đa dạng, dưới đây chúng tôi trích dẫn các câu trả lời của các em: phương pháp hoạt động nhóm giúp HS có thể "hiểu nhau hơn", "có nhiều sáng kiến hơn", 
giúp em "có thể thảo luận câu hỏi khó mà em không hiểu”, “...giúp em học nhanh và hiểu bài hơn”. Phương pháp dạy học trực quan giúp các em "dễ hiểu bài hơn", "giúp em hiểu từ mới và biết vật đó như thế nào", "giúp em dễ học và nhanh thuộc hơn", “...kích thích trí não và nhớ lâu hơn"...

Như vậy, đánh giá về mức độ sử dụng các phương pháp dạy học của $\mathrm{GV}$ trong các giờ học tiếng Anh, HS lớp 6 khẳng định $\mathrm{GV}$ thường sử dụng các phương pháp thuyết trình (là phương pháp phổ biến nhất), vấn đáp và trực quan. Trong khi đó, đây lại không phải là những phương pháp mà HS ưa thích nhất, giúp các em có hứng thú nhất bởi câu trả lời của HS đã khẳng định phương pháp dạy học mà HS hứng thú nhất là phương pháp dạy học qua các hoạt động nhóm và phương pháp dạy học trực quan.

Về mối tương quan giữa phương pháp dạy học của $G V$ và mức độ $K N G N$ từ tiếng Anh trợ hình thành và nâng cao các kỹ năng nghe và nói của $\mathrm{HS}$. Nghiên cứu này tập trung tìm hiểu việc sử dụng 2 loại phương tiện cơ bản khi dạy và học tiếng Anh, đó là phương tiện bên ngoài (các trang thiết bị phục vụ HĐHT tiếng Anh như đài cát xét, Ti vi và đầu video, máy projecter...) và phương tiện bên trong (chính là ngoại ngữ cần học). Bởi một trong những đặc trưng của hoạt động giảng dạy ngoại ngữ (đặc trưng về phương tiện) đó là HS sử dụng chính những từ ngữ được học làm phương tiện cho hoạt động học tập tiếp theo (Trần Hữu Luyến, 2008), tác giả gọi đây là phương tiện bên trong.

Qua tìm hiểu việc sử dụng các phương tiện hỗ trợ như đài cát xét, Ti vi và đầu video, máy projecter (phương tiện bên ngoài) trong giờ học tiếng Anh, chúng tôi thu được kết quả:

Bảng 4. Mức độ sử dụng các phương tiện, trang thiết bị dạy học tiếng Anh

\begin{tabular}{|c|c|c|c|c|c|c|c|}
\hline \multirow[b]{2}{*}{ TT } & \multirow[b]{2}{*}{ Phương tiện } & \multicolumn{5}{|c|}{ Mức độ sử dụng (\%) } & \multirow[b]{2}{*}{ ĐTB } \\
\hline & & $\begin{array}{c}\text { Không bao } \\
\text { giờ }\end{array}$ & Hiếm khi & $\begin{array}{l}\text { Thỉnh } \\
\text { thoảng }\end{array}$ & $\begin{array}{l}\text { Thường } \\
\text { xuyên }\end{array}$ & $\begin{array}{c}\text { Rất thường } \\
\text { xuyên }\end{array}$ & \\
\hline 1 & Máy projector & 26.5 & 27.4 & 19.6 & 26.5 & 0 & 2.46 \\
\hline 2 & Ti vi và đầu video & 40.0 & 18.0 & 21.0 & 21.0 & 0 & 2.23 \\
\hline 3 & Đài cát xét & 5.7 & 7.3 & 23.4 & 63.6 & 0 & 3.45 \\
\hline
\end{tabular}

của $\mathrm{HS}$, chúng tôi thấy rằng các yếu tố này có mối tương quan thuận và khá chặt $(\mathrm{r}=0.52$. $\mathrm{p}<0.01$ ). Phương pháp giảng dạy của $\mathrm{GV}$ có tác động khá lớn tới mức độ KNGN từ tiếng Anh của HS lớp $6 . \mathrm{GV}$ càng sử dụng nhiều phương pháp kích thích được tính tích cực hoạt động và hứng thú học tiếng Anh của HS bao nhiêu (chẳng hạn, phương pháp dạy học trực quan, hoạt động nhóm), HS càng ghi nhận được nhiều từ tiếng Anh và vận dụng chúng tốt hơn bấy nhiêu.

\subsubsection{Phuong tiện, trang thiết bi phục vu học tập tiếng Anh}

Các phương tiện, trang thiết bị là một yếu tố có vai trò rất lớn trong hoạt động học tập ngoại ngữ, đặc biệt là những phương tiện hỗ
Từ bảng số liệu có thể thấy đài cát xét là phương tiện được sử dụng phổ biến nhất (63.6\%), sau đó đến máy projector và $\mathrm{Ti}$ vi, đầu video. Thực tế ở các trường THCS, mỗi trường chỉ có một phòng máy. Trường hợp THCS Phương Canh có 2 phòng máy, một phòng có projector, một phòng có lắp Ti vi và sử dụng đầu video. Cả $\mathrm{GV}$ và $\mathrm{HS}$ đều khẳng định do có nhiều môn học nên không phải lúc nào cũng được dạy và học ở những phòng máy như vậy. Riêng HS lớp 6 trường THCS Cát Linh còn khẳng định chưa được học ở phòng có sử dụng máy projector lần nào, GV chỉ sử dụng đài ở trên lớp.

Ngoài những phương tiện học tập kể trên (là những phương tiện bên ngoài), hoạt động học tập ngoại ngữ có một phương tiện rất hiệu 
quả và không thể thiếu đó là việc sử dụng chính ngoại ngữ cần học làm phương tiện cho hoạt động học tập tiếp theo (phương tiện bên trong). Theo quan điểm dạy học ngoại ngữ hiện đại là hạn chế tối đa việc sử dụng tiếng mẹ đẻ trong dạy học ngoại ngũ̃, do đó HS học ngoại ngữ tới đâu sử dụng (vốn từ) luôn tới đó cho HĐHT ngoại ngữ tiếp theo. Việc hạn chế tối đa sử dụng tiếng mẹ đẻ trong lớp học ngoại ngữ được coi là môi trường tiếng lý tưởng cho người học ngoại ngữ nói chung và HS lớp 6 học tiếng Anh nói riêng. Đối với những câu hỏi về mức độ sử dụng tiếng Anh và tiếng Việt trong các giờ dạy, kết quả nghiên cứu cho thấy 65\% GV dạy tiếng Anh lớp 6 sử dụng cả tiếng Anh và tiếng Việt khi dạy, số lượng $G V$ trong quá trình dạy sử dụng nhiều tiếng Anh hơn tiếng mẹ đẻ chiếm tỉ lệ thấp hơn $(26.8 \%)$. Do đặc thù của môn học và lứa tuổi HS khi học môn học này, số lượng GV hoàn toàn sử dụng tiếng Anh chiếm tỉ lệ rất thấp.

Tìm hiểu tính tích cực của HS khi sử dụng tiếng Anh, mức độ HS thường xuyên nói chuyện với nhau bằng tiếng $\mathrm{Anh}$, kết quả cho thấy đa số HS thỉnh thoảng mới nói chuyện với nhau bằng tiếng Anh (42.7), 32.4\% HS hiếm khi nói chuyện, $14.9 \%$ HS không bao giờ nói chuyện với nhau bằng tiếng Anh. Số lượng $\mathrm{HS}$ thường xuyên nói chuyện bằng tiếng Anh chỉ chiếm $10 \%$ và không có $\mathrm{HS}$ nào khẳng định mức độ sử dụng tiếng Anh là rất thường xuyên. HS Việt Nam khi học ngoại ngữ nói chung và tiếng Anh nói riêng thường rất rụt rè, e ngại, không mạnh dạn trao đổi, trò chuyện với nhau bằng tiếng Anh. Đây là một trở ngại rất lớn cho HS khi học ngoại ngữ, bởi mục đích cuối cùng của việc học ngoại ngữ là có thể sử dụng được ngoại ngũ đó, đặc biệt là có thể giao tiếp bằng ngoại ngữ đó một cách thành thạo.

Tương tự như những phần trên, chúng tôi sử dụng hệ số Pearson để tìm ra mối tương quan giữa các phương tiện học tập với mức độ ghi nhớ từ của HS. Kết quả cho thấy tương quan giữa các phương tiện dạy học (bên trong và bên ngoài) với hiệu quả KNGN từ tiếng Anh có mối tương quan thuận với nhau, trong đó tương quan giữa phương tiện bên trong là mức độ thường xuyên sử dụng tiếng Anh để trò chuyện, giao tiếp với KNGN từ tiếng Anh chặt chẽ và mạnh hơn so với các phuong tiện bên ngoài. Có thể nói mức độ HS lớp 6 thường xuyên trò chuyện, giao tiếp bằng tiếng Anh càng nhiều bao nhiêu thì mức độ kỹ năng ghi nhận cách dùng từ tiếng Anh càng tốt bấy nhiêu $(\mathrm{r}=0.62, \mathrm{p}<0.01)$. Nói cách khác, khi học tiếng Anh, HS cần nỗ lực vận dụng phương tiện bên trong là vốn từ vừa mới được học vào các hoạt động lời nói tiếng Anh, mức độ HS vận dụng vốn từ đó để thực hành càng nhiều bao nhiêu thì càng ghi nhớ từ đó tốt hơn bấy nhiêu. Tuy nhiên, đáng tiếc là số lượng HS thường xuyên nói chuyện bằng tiếng Anh rất hạn chế, đa số HS chỉ thỉnh thoảng nói chuyện với nhau bằng tiếng Anh (ngoại ngữ mà các em đang học) nên hiệu quả của việc ghi nhớ từ chưa cao, cũng như kết quả thực tế của hoạt động học tập tiếng Anh còn rất thấp.

\section{Kết luận}

Từ những kết quả nghiên cứu trên, chúng tôi thấy trong phạm vi nghiên cứu này, các yếu tố mà chúng tôi tập trung tìm hiểu đều có mối tương quan thuận với KNGN từ tiếng Anh của HS lớp 6, nhưng mức độ ảnh hưởng của các yếu tố này là khác nhau.

Cụ thể, về phía yếu tố chủ quan, hứng thú học tiếng Anh là yếu tố có tác động khá mạnh tới KNGN từ của HS. Có thể nói, HS càng hứng thú học tiếng Anh bao nhiêu thì các em càng dễ dàng ghi nhớ được từ và cách dùng từ bấy nhiêu. Tuy nhiên, số lượng HS thực sự thích thú khi được học môn học này còn hạn chế, nhiều em vẫn chưa tự giác và dành ít thời gian học tiếng Anh, do đó hiệu quả HĐHT môn học này chưa cao. Nhận thức của HS về vai trò của từ vựng tuy có tương quan thuận với KNGN từ nhưng mối tương quan này không chặt, HS có thể có nhận thức đúng 
đắn về vai trò quan trọng của từ vựng khi học ngoại ngữ nhưng điều đó chưa đủ để khiến HS tích cực học tập và ghi nhớ từ tốt hơn. Vì vậy, trong những yếu tố chủ quan này, hứng thú học tập vẫn là yếu tố có tác động rõ rệt nhất tới hiệu quả học tập của HS.

Với những yếu tố khách quan, so với phương pháp giảng dạy của $\mathrm{GV}$, các điều kiện, phương tiện phục vụ hoạt động học tập tiếng Anh có ảnh hưởng, tác động mạnh hơn tới hiệu quả ghi nhớ từ tiếng Anh của HS. Cụ thể hơn, trong các phương tiện học tập, bên cạnh những phương tiện hỗ trợ học tiếng, một phương tiện rất quan trọng tác động trực tiếp tới hiệu quả học tập của các em chính là thứ ngoại ngữ các em cần học - phương tiện bên trong, bởi một trong những nguyên tắc học ngoại ngữ chính là học tới đâu sử dụng luôn tới đó làm phương tiện cho HĐHT tiếp theo. Kết quả xử lý số liệu cũng cho thấy yếu tố này có tương quan thuận và chặt chẽ tới mức độ ghi nhớ từ của HS. Các em càng tích cực giao tiếp bằng tiếng Anh bao nhiêu thì mức độ ghi nhớ từ, cách dùng từ càng hiệu quả bấy nhiêu. Mặc dù vậy, thực tế cho thấy hiệu quả học tập tiếng Anh của HS chưa cao vì số lượng HS thường xuyên nói chuyện, giao tiếp bằng tiếng Anh với bạn bè còn rất hạn chế, đa số HS mới chỉ thỉnh thoảng sử dụng tiếng Anh để trò chuyện, luyện tập thêm. Mặt khác, khi nói tới các phương tiện bên ngoài, mức độ $\mathrm{GV}$ sử dụng các thiết bị hiện đại, có tính trực quan cao trong giờ học ngoại ngữ còn thấp, GV chủ yếu vẫn chỉ sử dụng đài cát xét làm phương tiện hỗ trợ, các thiết bị có tính trực quan cao hơn như máy chiếu và đầu video ít được sử dụng. Điều này làm giảm hứng thú của HS và khiến các em ghi nhớ từ kém hiệu quả hơn.

Từ những kết quả trên, chúng tôi cho rằng GV giảng dạy tiếng Anh ở THCS nói riêng, và ở các bậc học nói chung cần lưu ý những đặc điểm này trong HĐHT tiếng Anh ở HS để có những điều chỉnh cụ thể, thiết thực hơn. GV cần thiết kế giờ học đa dạng, sinh động hơn, sử dụng các phương pháp dạy học trực quan, phương pháp làm việc nhóm nhiều hơn (theo như mong muốn của HS) để kích thích tính tích cực học tập, hứng thú học tập cho các em. GV cũng cần chú ý hạn chế sử dụng tiếng mẹ đẻ trong giờ học, tổ chức các hoạt động, các câu lạc bộ để HS có điều kiện thực hành tiếng nhiều hơn, Mặt khác, nhà trường cần tạo điều kiện để $\mathrm{GV}$ được sử dụng các thiết bị hiện đại phục vụ cho việc giảng dạy, thay vì chỉ có đài cát xét như hiện nay.

\section{Tài liệu tham khảo}

\section{Tiếng Việt}

Bộ Giáo dục và Đào tạo (2008). Đề án dạy và học ngoại ngũ trong hệ thống giáo dục quốc dân giai đoạn 2008 - 2020. Hà Nội , tr.28.

Trần Hữu Luyến (2008). Co sở Tâm lý học dạy học ngoại ngũ. Hà Nội: Nxb Đại học Quốc gia Hà Nội.

Trần Hũu Luyến (2012). Dạy học từ ngoại ngữ theo tiếp cận tâm lý học. Tâm lý học, số 8 (8/2012), tr.14.

\section{Tiếng Anh}

Karlin R. \& Karlin A. R. (1987). Teaching Elementary Reading: Principle and strategies $\left(4^{\text {th }}\right.$ Ed.). Harcourt Brace Jovanovich Publishers..

\section{Tài liệu từ các trang Web}

Folse, Keith S. (2004). Vocabulary Myths: Applying second language research to classroom teaching. University of Michigan Press, Ann Arbor. Available through <http://www.worddive.com/blog/wordswill-get-you-far-why-is-vocabulary-acquisitionso-important-in-second-and-foreign-languagelearning/>, Accessed 08/07/2017 10:56

Craik \& Lockhart (1972). The levels of processing model of memory. Available through

$<\mathrm{http}$ ://www.simplypsychology.org/levelsofprocessing. html>

Nation, Paul (1994). New Ways in Teaching Vocabulary. TESOL. Available through <http:// www.worddive.com/blog/words-will-get-you-farwhy-is-vocabulary-acquisition-so-important-insecond-and-foreign-language-learning/>, Accessed 08/07/2017 10:45

Robert S. Feldman, POWER Learning, 5th Edition, McGraw-Hill. Available through <https://www. inkling.com/read/power-learning-robert-feldman5th/chapter-8/determine-your-memory-style Accessed 19/9/2013 


\title{
INFLUENTIAL FACTORS TO SIXTH GRADERS' ENGLISH VOCABULARY MEMORIZATION SKILLS
}

\author{
Dao Thi Dieu Linh \\ Division of Educational Psychology, VNU University of Languages and International Studies, \\ Pham Van Dong, Cau Giay, Hanoi, Vietnam
}

\begin{abstract}
Vocabulary memorization is among the most essential skills in foreign language learning in general and English in particular. Our study of 216 sixth-graders and 11 English teachers in 2 Middle Schools in Hanoi using such methods as observation, survey questionnaires and interview shows that $6^{\text {th }}$ graders' vocabulary memorization is subject to several factors, including, inter alia, their awareness of the importance of vocabulary, their interest in learning English, teachers' pedagogical methods, supporting facilities and teaching aids. Of these, such internal factors as students' interest seem to exert the most apparent influence; their interest levels are proportionately relative to their lexical, syntactical and pragmatic knowledge of English words, i.e. how many words they can memorize, how well they can use them, to name just a few. Most influential external factors of importance include teaching aids and supporting facilities. Also, the more frequently students use English in everyday communication, the higher their competence and effectiveness in memorizing, recalling and using English words. Teachers should be aware of these factors to $6^{\text {th }}$ graders so that their lessons can be more effective and stimulating, which can arouse students' motivation and proactiveness in learning.
\end{abstract}

Keywords: memorizing English vocabulary, interest in learning English, influential factors 